\title{
Article \\ Effect of Extraction Methodology on the Phytochemical Composition for Camelia sinensis "Powdered Tea Extracts" from Different Provenances
}

\author{
Sérgio Barreira ${ }^{1} \mathbb{D}$, André M. N. Silva ${ }^{2} \mathbb{D}$, Carla Moutinho ${ }^{1}$, Ean-Jeong Seo ${ }^{3}$, Mohamed-Elamir F. Hegazy ${ }^{3,4} \mathbb{I D}$, \\ Thomas Efferth ${ }^{3}$ and Lígia Rebelo Gomes ${ }^{1,2, *(\mathbb{D})}$
}

1 FP-I3ID, CEBIMED, Universidade Fernando Pessoa, Praça 9 de Abril, 349, P-4249-004 Porto, Portugal; barreira@ufp.edu.pt (S.B.); carlamo@ufp.edu.pt (C.M.)

2 LAQV-REQUIMTE, Departamento de Química e Bioquímica, Faculdade de Ciências, Universidade do Porto, Rua do Campo Alegre, 687, P-4169-007 Porto, Portugal; andre.silva@fc.up.pt

3 Department of Pharmaceutical Biology, Institute of Pharmaceutical and Biomedical Sciences, Johannes Gutenberg University, Staudinger Weg 5, 55128 Mainz, Germany; seo@uni-mainz.de (E.-J.S.); mohegazy@uni-mainz.de (M.-E.F.H.); efferth@uni-mainz.de (T.E.)

4 Chemistry of Medicinal Plants Department, National Research Centre, 33 El-Bohouth St., Dokki, Giza 12622, Egypt

* Correspondence: lrgomes@ufp.edu.pt

check for

updates

Citation: Barreira, S.; Silva, A.M.N.; Moutinho, C.; Seo, E.-J.; Hegazy, M.-E.F.; Efferth, T.; Gomes, L.R. Effect of Extraction Methodology on the Phytochemical Composition for Camelia sinensis "Powdered Tea Extracts" from Different Provenances. Beverages 2022, 8, 13. https:// doi.org/10.3390/beverages8010013

Academic Editor: Quan V. Vuong

Received: 30 December 2021

Accepted: 17 February 2022

Published: 23 February 2022

Publisher's Note: MDPI stays neutral with regard to jurisdictional claims in published maps and institutional affiliations.

Copyright: (C) 2022 by the authors. Licensee MDPI, Basel, Switzerland. This article is an open access article distributed under the terms and conditions of the Creative Commons Attribution (CC BY) license (https:// creativecommons.org/licenses/by/ $4.0 /)$.

\begin{abstract}
Background: beverages based on extracts from Camellia sinensis are popular worldwide. Due to an increasing number of processed teas on the market, there is a need to develop unified classification standards based on chemical analysis. Meanwhile, phytochemical characterizations are mainly performed on tea samples from China ( $80 \%)$. Hence, data on teas of other provenances is recommended. (2) Methods: in the present investigation, we characterized lyophilised extracts obtained by infusion, maceration and methanolic extraction derived from tea samples from China, Japan, Sri Lanka and Portugal by phytochemistry (catechins, oxyaromatic acids, flavonols, alkaloids and theanine). The real benefits of drinking the tea were analysed based on the bioavailability of the determined phytochemicals. (3) Results: the infusions revealed the highest total phenolic contents (TPC) amounts, while methanolic extracts yielded the lowest. The correlation matrix indicated that the levels of phenolic compounds were similar in the infusions and methanolic samples, while extractions made by maceration were significantly different. The differences could be partially explained by the different amounts of (-)-epigallocatechin gallate (EGCG), (-)-epicatechin gallate (ECG) and gallic acids (GA). The catechin percentages were significantly lower in the macerations, especially the quantity of EGCG decreases by 4 - to 5 -fold after this process. (4) Conclusions: the results highlight the importance of the processing methodology to obtain "instant tea"; the composition of the extracts obtained with the same methodology is not significantly affected by the provenance of the tea. However, attention should be drawn to the specificities of the Japanese samples (the tea analysed in the present work was of Sencha quality). In contrast, the extraction methodology significantly affects the phytochemical composition, especially concerning the content of polyphenols. As such, our results indicate that instant tea classification based on chemical composition is sensible, but there is a need for a standard extraction methodology, namely concerning the temperature and time of contact of the tea leaves with the extraction solvent.
\end{abstract}

Keywords: phytochemical composition; Camellia sinensis; HPLC; catechins; natural product; Theaceae

\section{Introduction}

Tea (Camellia sinensis (L.) Kuntze (Theaceae)) is one of the oldest beverages in the world. Although Pacific Asia is the dominant region for tea drinking, consumption of tea and teabased beverages have been increasing in Europe and in USA. According to recent statistics (2017), 68\% of people in the UK drink tea day to day, and over 159 million Americans 
drink tea every day. The global market for tea revenue is about US\$214,761 million and is expected to grow each year by $6.9 \%$ until 2023 (https:/ / www.statista.com/outlook/cmo/ hot-drinks / tea/worldwide, accessed on 21 June 2021). In fact, tea is nowadays a drink associated with several health benefits and has been adopted by stressed urban consumers. Consuming green tea prevents lifestyle-related diseases and, therefore, reduces morbidity as reported by several studies [1], including cancer [2-5], and cardiovascular diseases [6-8]. Several epidemiological studies have showed that tea consumption is associated with decreased mortality rates due to lifestyle-related diseases [9-13].

In addition, the COVID-19 pandemic pushed up the consumption of tea worldwide. Consumers perceive tea as a healthy drink with a variety of benefits related to the ability of its constituents to act as a booster of the human immune systems. For instance, recent studies suggest that EGCG may inhibit the replication of SARS-CoV-2 [14].

Despite its popularity, tea cultivation is confined to certain regions of the world due to specific requirements of climate and soil. Most of the tea is produced in Asia, with China, India and Sri Lanka being the main producers. The oldest location for producing green tea on the European continent is the Azores Islands, an archipelago located in the westernmost part of Europe. Due to the increase in the availability of many processed teas, as an alternative to the classic six tea types, there is a need to develop a standard for tea classification based on chemical analysis, as a substitute to the classic classification based on the processing methods, as recognised by experts from the International Organization for Standardization. Meanwhile, the sources for quantities of phytochemicals in sample teas are mostly coming from China ( 80\%) (https:/ / www.iso.org/committee/47918.html, accessed on 30 September 2021) and as such, data on phytochemical quantification of tea deriving from other provenances is recommended to increase data diversity. In addition, most of the published data do not follow the accepted standard guidelines concerning, e.g., good practice for sampling, standardisation for extraction methods and profiling the phytochemicals.

We have previously quantified the constituents of tea cultivated in the Azores (Portugal) [15]. However, we come across difficulties getting useful data, when searching for analytical results concerning the phytochemical composition of green teas harvested in different Asian areas for comparison purposes. This problem arises from the non-standardized diversity of extraction methods and conditions of analytical methodologies. Consequently, we realized there was a need to quantify phytochemicals of tea samples cultivated in other countries, using identical techniques and conditions for quantification and extraction. Thus, the composition of infusions, macerations and methanolic extracts of teas from China, Japan and Sri Lanka were determined by HPLC-DAD. While infusion is the method of preparation of tea from leaves or powdered leaves, "instant tea" is becoming more and more used. Hence composition analysis of extracts from other mediums and/or with higher extraction times are useful for comparison. Thus, the results of the phytochemical characterizations (catechins, oxyaromatic acids, flavonols, alkaloids and L-theanine) are presented and discussed in a comparative way. Furthermore, an analysis of the real benefits of drinking the tea is made based on data concerning the bioavailability of the determined phytochemicals.

The analysis of the results will allow an assessment to be made of the extent of the influence of pedoclimatic factors on the composition of the teas. This will contribute with data to the development of quality standards and will verify the differences in compositions of extracts that are due to extraction methodologies, assuming the latter have a special relevance in industrial production of "powdered tea extracts".

\section{Materials and Methods}

\subsection{Solvents, Reagents and Standards}

Commercial samples of green tea leaves of various provenances were purchased on the Portuguese market. Samples were identified according to their provenance as $\mathbf{A}$ for Azores (Green tea Gorreana), C for China (Green tea from China), J for Japan (Japanese 
Sencha green tea) and SL (Pure green tea from Sri Lanka). The teas used for extraction were gathered after blending samples from different batches.

All solvents and reagents from various suppliers were of the highest purity needed for each application. Methanol (LC-MS) and formic acid (p.a.) were obtained from Fluka Analytical (Munich, Germany), acetonitrile (LC-MS) from Sigma-Aldrich (Steinheim, Germany). The Folin-Ciocalteu reagent was from Merck. Reference standards of L-theanine (>99\%), caffeine $(>99 \%)$ and (-)-epigallocatechin gallate $(>99 \%),(+)$-catechin $(>99 \%),(-)$-epicatechin $(>99 \%),(-)$ epicatechin gallate $(>99 \%),(-)$-epigallocatechin $(>99 \%)$ gallic acid $(>99 \%)$, kaempferol-3-glucoside (>99\%) neochlorogenic acid (>99\%) o-caffeoylquinic acid (>99\%) quercitin-3-D-galactoside (>99\%) were purchased from Sigma-Aldrich Corp (St. Louis, MO, USA). Water from a Milli-Q purification system (Simplicity- UV. Millipore Corp. France) was used for sample preparation and analysis.

All standards were prepared as stock solutions in methanol or water (theanine). Working standards were made by diluting stock solutions to yield concentrations ranging between $5 \mu \mathrm{g} \times \mathrm{mL}^{-1}$ and $10 \mathrm{mg} \times \mathrm{mL}^{-1}$.

Stock/working solutions of the standards were stored in darkness at $-18{ }^{\circ} \mathrm{C}$.

\subsection{Extraction Methodology}

Extraction method 1 (tea infusions): hot tea infusions were prepared for samples coming from China (C), Japan (J) and Sri Lanka (SL) by pouring purified water at $90{ }^{\circ} \mathrm{C}$ on $1.5 \mathrm{~g}$ of tea and brewing for 5-7 min according to commercial indications. They were then filtered through Whatman membrane filters $0.45 \mu \mathrm{m}$, lyophilised and stored, yielding dry extracts [\% $(w / w)$ ] of $43.2 \%$ for C1, $18.3 \%$ for J1 and $20.0 \%$ for SL1.

Extraction method 2 (aqueous macerations): $1.5 \mathrm{~g}$ of one type of green tea was placed in a $250 \mathrm{~mL}$ Schott flask and $100 \mathrm{~mL}$ water was added. The flask was covered, and the plant was macerated for $48 \mathrm{~h}$ at room temperature in the dark. The $\mathrm{pH}$ of the extracted aqueous solutions was less than 5.0. The water fraction was removed by filtration through Whatman membrane filters mixed cellulose ester $0.45 \mu \mathrm{m}$, lyophilised and stored yielding dry extracts [\% $(w / w)]$ of $20.6 \%$ for C2, 26.2\% for $\mathbf{J} 2$ and $33.8 \%$ for SL2.

Extraction method 3 (methanolic extracts): dried plant material $(1.5 \mathrm{~g})$ was thoroughly mixed with methanol $(3 \times 50 \mathrm{~mL})$ for $20 \mathrm{~min}$. Collected extracts were filtered and centrifuged (3000 rpm. $15 \mathrm{~min}$ ) and the solvent was evaporated, yielding dry extracts [\% ( $w / w)$ ] of $12.5 \%$ for $\mathbf{C} 3,6.4 \%$ for J3 and $11.3 \%$ for SL3. All powdered extracts were kept frozen $\left(-18{ }^{\circ} \mathrm{C}\right)$ until further use.

\subsection{Total Phenolics Content (TPC)}

Total phenolics were estimated using the Folin-Ciocalteu colorimetric following a method described previously [16] with a small modification. Briefly, $300 \mu \mathrm{L}$ of the extract $\left(1 \mathrm{mg} \times \mathrm{mL}^{-1}\right)$ was diluted in a $10.0 \mathrm{~mL}$ volumetric flask to which $1.0 \mathrm{~mL}$ undiluted Folin-Ciocalteu reagent was added. Immediately $5.0 \mathrm{~mL} 20 \%(w / v) \mathrm{Na}_{2} \mathrm{CO}_{3}$ was added. After $30 \mathrm{~min}$ incubation at room temperature, the absorbance was measured at $735 \mathrm{~nm}$ and compared to a pre-prepared gallic acid calibration curve. Determinations were performed in triplicate. Results were expressed as milligram of gallic acid equivalents (GAE) per gram of extract.

\subsection{HPLC-DAD Analysis}

The analysis was performed using the same methodology applied previously for characterization of green tea coming from the Azores [15]. An analytical HPLC unit with diode-array detection device (Thermo Scientific Dionex Ultimate 3000 (Thermo Fisher Scientific Inc., Germering, Germany) $)$ equipped with a C18 column $(15.0 \times 0.46 \mathrm{~cm}, 5 \mu \mathrm{m}$ particle size) from Supelco was employed. The solvent system used was a gradient of water-formic acid (19:1) (A) and methanol (B). At a solvent flow rate of $0.9 \mathrm{~mL} / \mathrm{min}$ and starting with $5 \%$ methanol, a gradient was implemented to obtain $15 \% \mathrm{~B}$ at $2 \mathrm{~min}$, $25 \% \mathrm{~B}$ at $8 \mathrm{~min}, 30 \% \mathrm{~B}$ at $15 \mathrm{~min}, 35 \% \mathrm{~B}$ at $21 \mathrm{~min}, 45 \% \mathrm{~B}$ at $23 \mathrm{~min}, 45 \% \mathrm{~B}$ at $25 \mathrm{~min}$, 
$50 \% \mathrm{~B}$ at $26 \mathrm{~min}, 55 \% \mathrm{~B}$ at $28 \mathrm{~min}, 70 \% \mathrm{~B}$ at $30 \mathrm{~min}, 75 \% \mathrm{~B}$ at $34 \mathrm{~min}$ and $80 \% \mathrm{~B}$ at $36 \mathrm{~min}$. Spectral data from all peaks were accumulated in the range $200-400 \mathrm{~nm}$, and chromatograms were recorded at 280,320 and $350 \mathrm{~nm}$. For all analyses the injection volume was $10 \mu \mathrm{L}$, and oven temperature was controlled at $25^{\circ} \mathrm{C}$. Chromatographic data was processed with a Chromeleon ${ }^{\mathrm{TM}}$ 7.2 Chromatography Data System Software (Thermo Fisher Scientific Inc., Germering, Germany). Peak integration was performed automatically using baseline-to-baseline integration. When necessary (noisy baseline or co-eluting peaks), a manual correction of erroneous automated data system integrations was performed. The compounds in each sample were identified and quantified by comparing their retentions times and peak area in the chromatograms relative to external standards.

The quantification of theanine was performed according to Song et al. [17] at $200 \mathrm{~nm}$ using the following elution program with a flow rate of $1 \mathrm{~mL} / \mathrm{min}: 0-2 \mathrm{~min}: 2 \%$ acetonitrile, 98\% ultrapure water; 2-20 min: percentage of acetonitrile increased linearly from $2 \%$ to 20\%; 20-25 min: percentage of acetonitrile increased linearly from $20 \%$ to $21 \%$; 25-35 min: $50 \%$ acetonitrile, 50\% ultrapure water; 35-40 min: percentage of acetonitrile decreased linearly from $50 \%$ to $2 \%$; and, $40-45 \mathrm{~min}$ : $2 \%$ acetonitrile, $98 \%$ ultrapure water.

\subsection{Statistical and Data Analysis}

A completely randomized design was used with three replications. Statistical analysis was performed using SPSS v. 24 (IBM Corp. Armonk, NY, USA). Data for all analyses were expressed as mean \pm standard error. Analysis of Variance (ANOVA) followed by Tukey's HSD post-hoc test for multiple comparisons was used to assess the statistical differences among means $(p \leq 0.05)$. The graphical representations were made with Sigma Plot V10.

\section{Results}

Values obtained for the total phenolics content (TPC) expressed in mg GAE/g extract are presented in Table 1. In Table S1 the sum of all the phenolic compounds (sum phenolic) measured by HPLC-DAD is shown as well as the quantified (-)-epicatechin (EC), (-)-epicatechin gallate (ECG), (-)-epigallocatechin (EGC), (-)-epigallocatechin gallate (EGCG) and (+)-catechin (C). This table also contains the amounts of quercetin-3D-galactoside (Q-3-gal), kaempferol-3-glucoside (K), and the oxyaromatic acids 3-Ocaffeoylquinic (o-CQA) and neochlorogenic (5-O-caffeoylquinic) (NCA), and gallic acids (GA). Table S2 lists the quantification of the alkaloids (caffeine and theophylline) and the amino acid L-theanine.

Table 1. Total phenolic content and antioxidant activity in green teas of different geographic provenance: C (China); A (Azores); J (Japan); SL (Sri Lanka); (1-infusion, 2-maceration, 3-methanolic extract).

\begin{tabular}{ccl}
\hline Tea Sample & $\begin{array}{c}\text { TPC * } \\
\text { (mg GAE/g Extract) }\end{array}$ & Ref. \\
\hline C1 & $92.883 \pm 3.196^{\mathrm{d}}$ & This work \\
C2 & $65.007 \pm 1.399^{\mathrm{f}}$ & This work \\
C3 & $56.017 \pm 1.125^{\mathrm{g}, \mathrm{h}}$ & This work \\
\hline A1 & $151.843 \pm 6.857^{\mathrm{a}}$ & {$[15]$} \\
A2 & $111.793 \pm 1.575^{\mathrm{b}}$ & {$[15]$} \\
A3 & $85.179 \pm 1.776^{\mathrm{d}, \mathrm{e}}$ & {$[15]$} \\
\hline J1 & $79.147 \pm 1.976^{\mathrm{e}}$ & This work \\
J2 & $62.133 \pm 2.052^{\mathrm{f}, \mathrm{g}}$ & This work \\
J3 & $52.087 \pm 1.126^{\mathrm{h}}$ & This work \\
\hline SL1 & $102.927 \pm 4.636^{\mathrm{c}}$ & This work \\
SL2 & $80.683 \pm 1.168^{\mathrm{e}}$ & This work \\
SL3 & $63.384 \pm 1.125^{\mathrm{f}, \mathrm{g}}$ & This work \\
\hline
\end{tabular}

* Values expressed as mean \pm standard deviation obtained from 3 measurements per replicate. For each parameter different lowercase superscripts indicate statistically significant differences $(p<0.05)$. 
Typical chromatograms are presented in Figure 1 providing evidence for the differences in phytochemical profiles of the tea samples studied. Because different extraction methods led to different amounts of crude extract, the contents of phenolic were expressed in in $\mathrm{mg} / \mathrm{g}$ of extract.
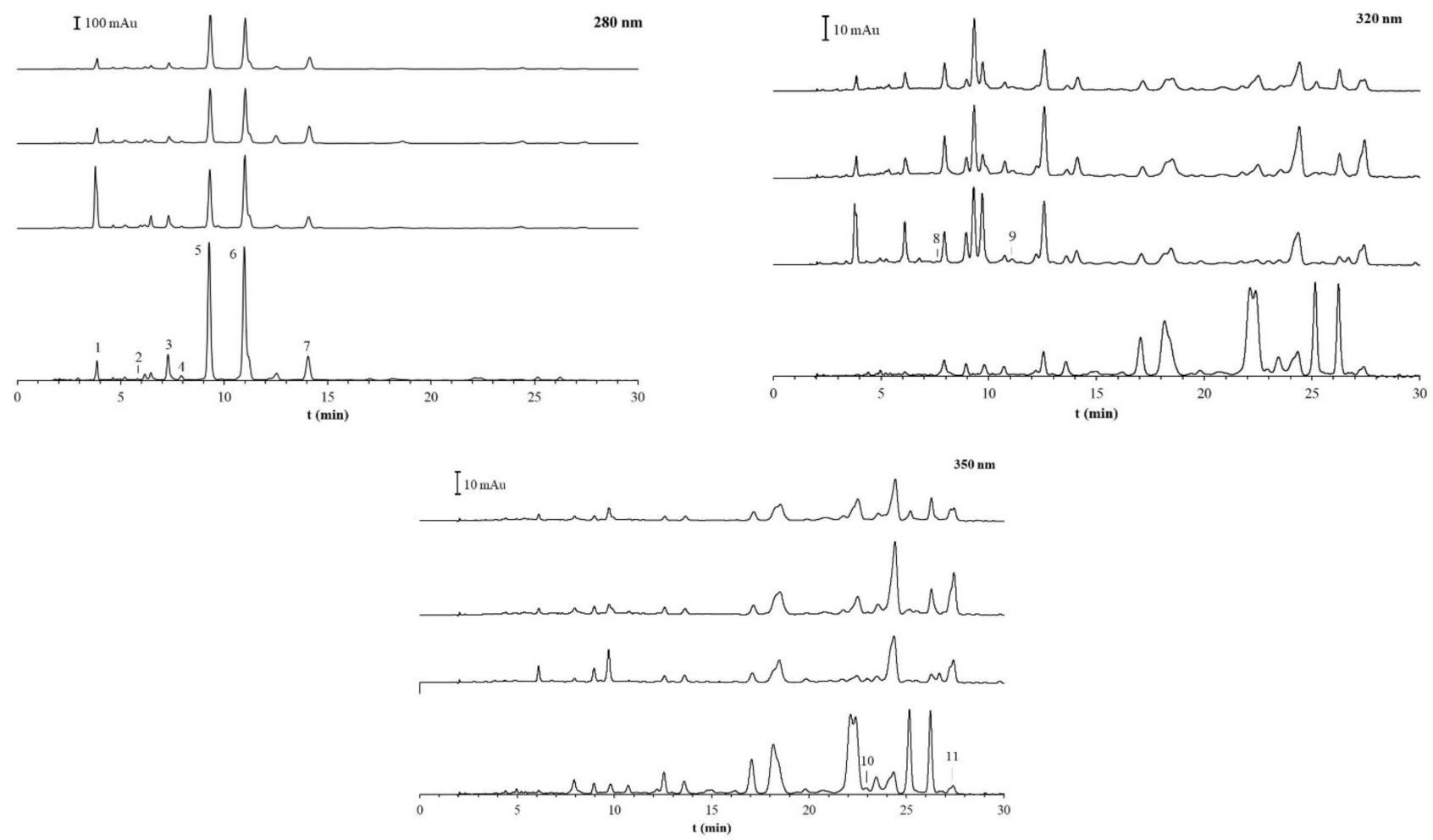

Figure 1. HPLC profile of the green tea extracts at different wavelengths; in each wavelength and from top to bottom: China tea; Azores tea; Japan tea; Sri Lanka Tea. (1) gallic acid, (2) neochlorogenic acid, (3) epigallocatechin, (4) 4-O-caffeoylquinic acid, (5) epigallocatechin-3-gallate, (6) caffeine, (7) epicatechin-3-gallate, (8) (+)-catechin, (9) epicatechin, (10) quercetin-3-galactoside, (11) kaempferol3-glucoside.

\section{Discussion}

In the present work, extractions were performed with two different solvents: methanol and water. The aqueous extracts were obtained by maceration (room temperature) and by infusion. Infusions were made following the instructions for preparation from the producers. All protocols were performed with the same conditions as in a previous work [15].

It has been reported that the content of alkaloids and catechins in green tea varies with different plucking periods [18]. In order to diminish the differences in composition arriving from such variability, the material used for extraction was gathered after blending samples of teas coming from different batches, in accordance with the guidelines on quality of herbal medicinal products/traditional medicinal products from the European Medicines Agency Inspections.

As regards the selection of solvents (water vs. methanol) for extraction, even if only the differences in the dissolution capacities are considered, aqueous and methanolic extracts are expected to differ in composition, namely regarding the secondary metabolites that will affect the total phenols content. In particular, methanol has been generally found to be more efficient in extraction of lower molecular weight polyphenols, while the higher molecular weight flavanols were better extracted with water [19]. For instance, the total catechins content (TCC) of commercial samples of green teas may vary within the range of [21.4-228.2] $\mathrm{mg} /$ ( $\mathrm{g}$ dry tea) for aqueous extractions and within the range [32.2-141.2] mg/(g dry tea) for methanolic extracts [20]. Extractions with mixtures 
of methanol/water tended to yield higher amounts of catechins than those of absolute methanol. It is interesting to note that the range of concentrations for the aqueous extracts was larger than that of the corresponding methanol extraction, but this could be because yields of powder obtained for water extractions were more variable than those obtained for methanol. The TCC for the studied samples varied within the [39.4-98.9] mg/(g of dry tea) range for infusions and within the [11.5-21.4] $\mathrm{mg} /(\mathrm{g}$ of dry tea) range for methanolic extractions. The methanolic extractions led to lower catechins content probably because methanol at $99 \%$ was used.

For a particular solvent, the amounts of extracted components also depended on the extraction conditions. Extraction is a process mainly governed by diffusion and solubility. Longer extraction periods and higher temperatures promote increased permeability of cell walls of green tea leaves and can enable more tea catechins to move into the solution, as these conditions enhance the solubility and diffusion coefficients. However, the solubility of the individual catechins in the solvent may differ due to their different structure and molecular weight. In addition, the stability of the catechins may be affected, if tea is brewed for too long, because of an increased probability of epimerization, oxidation, and degradation, especially under higher extraction temperatures [21]. Also, $\mathrm{pH}$ seems to affect the percentages of catechins extraction due to decomposition. At $\mathrm{pH} 6$ and 7, the epistructured catechins were partially epimerized to non-epistructured catechins and both groups were degraded for $\mathrm{pH}>9$ [22].

\subsection{Total Phenolic Content (TPC) and Total Phenolics}

According to Uchenna et al. [20], the mean value for TPC (mg GAE/g dry tea) presented by samples of green teas consumed in UK was $77.2 \mathrm{mg} / \mathrm{g}$, ranging from 65.8 to $106.2 \mathrm{mg} / \mathrm{g}$. The obtained values were within this range except for the Azorean infusion that was higher. Independently of the provenance, the data suggest that the TPC varied as follow: TPC (infusions) > TPC (macerations) > TPC (methanolic), see Table 1. Although a higher TPC is related to a more effective antioxidant sample, the measured TPC for each sample should be regard as related to the activity of a unique set of antioxidant substances: for instance, the antioxidant activities of the infusions and methanolic extracts are probably due to the higher content of catechins, while the high concentration of GA in maceration suggests that this substance is the main contributor to the antioxidant activity.

In Table S1, the sum of all the phenolic compounds (sum phenolic) measured by HPLC-DAD is shown in column 7 and total catechins content (TCC) in column 8. Catechins, flavonols and oxyaromatic acids were the major flavonoids in green teas. Catechins themselves can comprise about $90 \%$ of the phenolic compounds. The phytochemical analysis of the studied samples also showed that catechins were prevalent among the phenolics, as seen by the ratio of TCC/TPC that rose to $90 \%$. However, exceptions were the maceration extracts of samples from China, Azores, and Sri Lanka (C2, A2 [15] and SL2) and infusions from Japan (J1). Contributing to these observations were the lower or undetected concentrations for EGCG in the macerates of the teas from China, Azores, and Sri Lanka and the high value for GA in the Japan infusion sample. The comparative discussion of samples made in the next section will show that maceration solutions have a different composition to the others. Therefore, it looks as if catechins were responsible for the TPC in infusions and methanolic extracts, while in macerations GA could be a major contributor.

\subsection{Phytochemical Characterization: Chromatographic Fingerprinting and Marker Compound Analysis}

Chromatographic methods such as HPLC-DAD are the methods of choice for the analysis of multicomponent mixtures in tea. There are 12 catechins in total that could be identified by chromatography but epigallocatechin gallate and epigallocatechin were the most abundant ones, taken as constitutive of $70 \%$ of the total amount [23]. 


\subsubsection{Phenolic Content}

Considering the number of the samples and of the quantified substances, the analysis of the similarity of composition in terms of phenolics was made by means of a correlation matrix (Figure 2). The matrix was made considering the previous results of the tea from the Azores [15] and shows the correlation between the samples within their composition: positive values indicate that the samples correlate directly; negative values indicate that samples correlate inversely. Values shown in red were indicative of statistically sound correlations (at a statistical level of 2 hence, they may be considered as being similar. Black values were less than 0.8 and were indicative for samples showing a weak correlation, which can be thus assumed as being different.

\begin{tabular}{|c|c|c|c|c|c|c|c|c|c|c|c|c|}
\hline & $C 1$ & $C 2$ & C3 & $A 1$ & $A 2$ & A3 & $J 1$ & $J 2$ & $J 3$ & SL1 & SL2 & SL3 \\
\hline$C 1$ & 1 & & & & & & & & & & & \\
\hline$C 2$ & 0.719 & 1 & & & & & & & & & & \\
\hline C3 & 0.923 & 0.546 & 1 & & & & & & & & & \\
\hline$A 1$ & 0.990 & 0.766 & 0.930 & 1 & & & & & & & & \\
\hline$A 2$ & 0.223 & 0.775 & -0.020 & 0.259 & 1 & & & & & & & \\
\hline$A 3$ & 0.950 & 0.620 & 0.992 & 0.964 & 0.065 & 1 & & & & & & \\
\hline$J 1$ & 0.936 & 0.896 & 0.793 & 0.939 & 0.545 & 0.841 & 1 & & & & & \\
\hline$J 2$ & 0.986 & 0.802 & 0.860 & 0.983 & 0.344 & 0.904 & 0.964 & 1 & & & & \\
\hline$J 3$ & 0.964 & 0.605 & 0.991 & 0.965 & 0.062 & 0.996 & 0.852 & 0.915 & 1 & & & \\
\hline SL1 & 0.994 & 0.668 & 0.928 & 0.973 & 0.153 & 0.943 & 0.910 & 0.971 & 0.963 & 1 & & \\
\hline SL2 & -0.095 & 0.514 & -0.246 & -0.066 & 0.896 & -0.202 & 0.256 & -0.001 & -0.202 & -0.145 & 1 & \\
\hline SL3 & 0.936 & 0.607 & 0.989 & 0.953 & 0.069 & 0.997 & 0.828 & 0.886 & 0.991 & 0.924 & -0.191 & \\
\hline
\end{tabular}

Figure 2. Correlation matrix for polyphenol composition of the samples analysed. Compositions of infusions correlated significantly $(p<0.05)$ with compositions of methanolic extracts, but not with maceration extracts. C-China tea; A-Azores tea; J-Japan tea; SL-Sri Lanka Tea; 1-Infusion; 2-Maceration; 3-Methanolic extract.

Comparing extracts obtained by the same extraction methodology, the data indicates that infusions did not significantly differ in terms of their polyphenol composition, regardless of the provenance of the sampled tea. The same conclusion can be drawn when the methanolic extracts were compared with each other. In contrast, maceration extracts showed significant differences in composition between samples, but macerates of the Chinese tea were similar to those of Japan tea (see cells $\mathbf{C 2} / \mathbf{J} 2$ ), and the composition of the Azorean maceration was not significantly different from that coming from Sri Lanka (see cell A2/SL2).

With respect to the comparison of extracts made with different extraction methods, it could be easily noted that maceration extracts differed significantly from those obtained by infusion and by methanol: the correlation coefficients in the columns/rows for the maceration samples $\mathbf{C} \mathbf{2}, \mathbf{A} \mathbf{2}, \mathbf{J} \mathbf{2}$ and $\mathbf{S L} \mathbf{2}$ were mostly less than 0.80 , except for the Japanese sample. In addition, maceration of the Chinese tea sample yielded an extract that was 
similar to the Japanese infusion $(\mathbf{C} 2 \approx \mathbf{J} 1)$, while the methanolic extract of the Chinese sample was different from the infusion of the Japanese sample $(\mathbf{C} \mathbf{3} \neq \mathbf{J} \mathbf{1})$.

\subsubsection{Levels of Catechins}

Polyphenols are responsible for many of the healthy properties attributed to green tea intake. The most abundant polyphenol is EGCG and is also responsible for most of the health benefits [24]. Our results show that the content of EGCG varied between 19.6 and $68.1 \mathrm{mg} /$ ( $\mathrm{g}$ tea leaves), giving a total amount of 98-340 $\mathrm{mg}$ per cup if a bag of $5 \mathrm{~g}$ is considered. The amount of EGCG in the $\mathbf{J}$ and A samples were similar $(19.4 \pm 0.9$ and $22.9 \pm 1.6 \mathrm{mg}$, respectively), while the $\mathrm{C}$ sample revealed approximately double $(42.6 \pm 4.1 \mathrm{mg})$ and the SL sample triple $(68.1 \pm 14.2 \mathrm{mg})$ that of the others.

More important than the quantity extracted is the amount of catechins available for absorption. This will provide the realistic dose that will give a certain benefit. Catechins are compounds that are bioavailable after consumption. Both EGCG and ECG are detectable in plasma, and it seems that they are transported and stabilized by serum albumin [25]. Both EC and EGC appear in the blood stream as metabolized glucuronide or sulphate conjugates. The consumption between 50 and $250 \mathrm{mg}$ yielded maximal EGCG levels in the blood of about $60 \% 1.5$ to $2 \mathrm{~h}$ after intake giving a bioavailability that varies from about 60 to $204 \mathrm{mg}$ per cup for our samples [26,27].

If tea preparations are made as "soluble tea", then a lyophilized powder is likely to be used. Values obtained for the catechins composition of the lyophilized samples are shown in Table S1 and in the graphic representations of Figure 3, (a) for infusions, (b) for methanolic and (c) for maceration extracts. Previously obtained data from tea samples of the Azores [15] have also been included into the graphics for comparison.

The prevalent catechins in the infusions were EGCG, EGC and EC with SL tea showing the highest content. The concentration of EGCG varied from 100 to $150 \mathrm{mg} /(\mathrm{g}$ extract), i.e., it accounted for $10-15 \%$ of the entire extract amount. This is in accord with most literature data [24]. Cathechin appeared in a very low quantity if compared with the remaining ones (see Figure 3). The quantities of EGC and EC extracted were lower than $80 \mathrm{mg} / \mathrm{g}$ and of EGG less than $4 \%$ of the extract.

Aqueous and methanolic extracts are expected to differ in composition due to the differences in dielectric constants and polarities of the solvents. Previous results suggest that methanol has been generally found to be more efficient in extracting low molecular weight polyphenols [19]. However, our results suggest that methanol seems to be as effective for catechin extraction as water except for $C$ that was not detected by HPCL-DAD in the methanolic samples. Also, the highest catechin content was found in the A sample (Figure 3). These results suggest that methanol was more efficient in extracting EC and EGG than water.

For a particular solvent, the amounts of extracted components also depend on the extraction conditions. Extraction is a process mainly governed by diffusion and solubility. These variables are usually enhanced by longer extraction times and/or higher temperatures. The increment on the solubility of the individual catechins in the solvent may differ due to their different structures and molecular weights. In addition, the stability of the catechins may be affected, if tea is brewed for too long because of an increased probability of epimerization, oxidation, and degradation, especially under higher extraction temperatures [21]. Our results indicate that the permanency of tea leaves in contact with water for a long maceration period $(48 \mathrm{~h})$ had a considerable effect on the extract contents of catechins (Figure 3a,c). Therefore, it can be concluded that the catechin content significantly contributes to the differences in composition between macerations and methanolic extracts/infusions, as already inferred in the analysis of the correlation matrix. Meanwhile, the quantification of the individual catechins shows that there was no significant difference in the amounts of EC, EGC and C extracted by maceration and infusion (Figure 3a,c, same scale). In contrast, the amounts of EGCG and ECG were different: In the SL sample, EGCG was reduced from $141.01 \pm 11.54 \mathrm{mg} / \mathrm{g}$ in the infusion to an undetectable level in macera- 
tion; in the $C$ samples, it was reduced from $105.65 \pm 10.21$ to $35.93 \pm 3.19 \mathrm{mg} / \mathrm{g}$; and in the A samples from $105.13 \pm 7.16$ to $9.28 \pm 1.42 \mathrm{mg} / \mathrm{g}$.

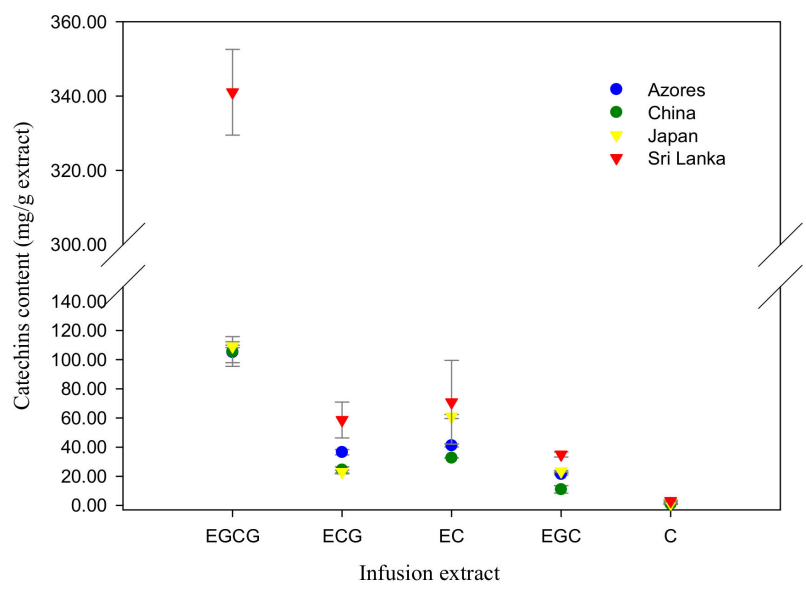

(a)

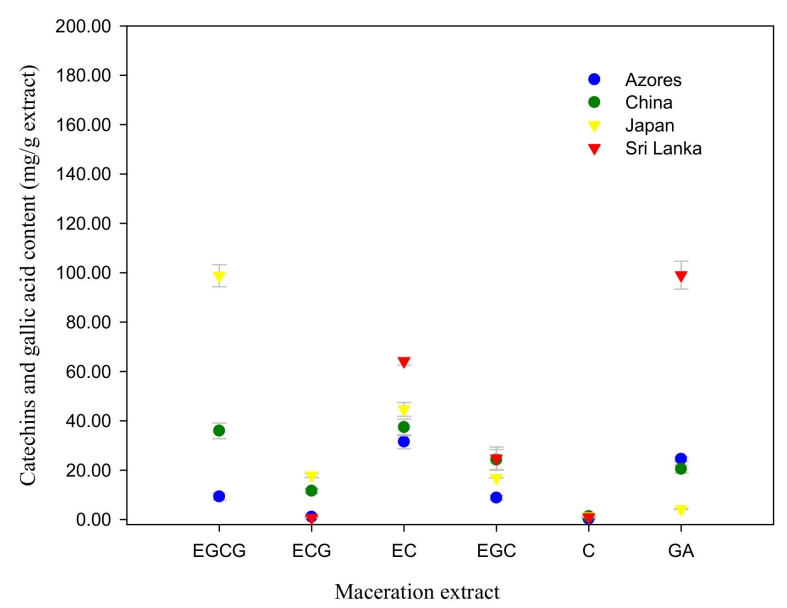

(c)

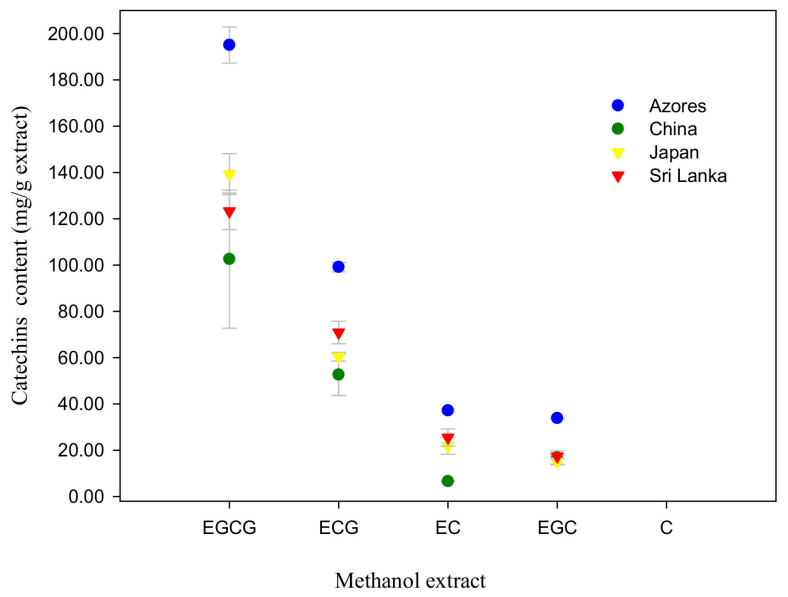

(b)

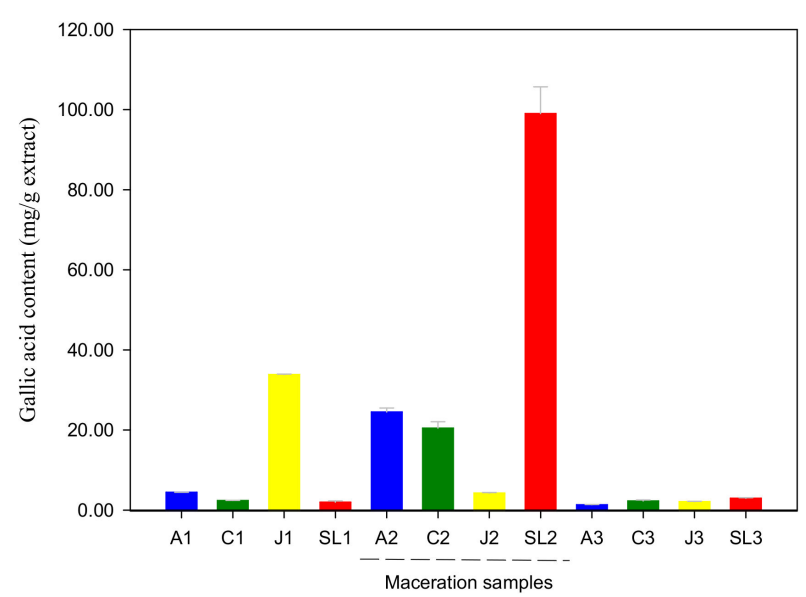

(d)

Figure 3. Content of catechins in green teas in $\mathrm{mg} / \mathrm{g}$ of extract of the samples, determined by HPLC (mg/g extract); (a) Infusions; (b) Methanolic extractions; (c) Macerations; (d) GA contents in all samples; C-China tea; A-Azores tea; J-Japan tea; SL-Sri Lanka tea; 1-Infusion; 2-Maceration; 3-Methanolic extract.

An exception was the $\mathbf{J}$ tea, where the catechin EGCG and ECG contents did not significantly vary. In addition, when looking for the GA amounts (Figure 3d), the quantity of GA extracted in the $\mathbf{J}$ by infusion was significantly higher than the others, while the GA content increased by maceration for A, C and SL teas relative to infusions. In short, the amounts of the galleted catechins lowered from infusion to maceration, but this trend was not noticed in the $\mathbf{J}$ sample. The opposite happened concerning GA. This may be explained by the occurrence of hydrolysis during maceration, as previously shown accordingly [28]. These authors concluded that epigallocatechin (EGC) and gallic acid (GA) may be prepared by degalloylation of an epigallocatechin gallate (EGCG) extract from green tea by enzymatic catalysis. The catechins in the SL sample tea seem to be particularly sensitive to hydrolysis. The Japanese tea did not follow this pattern: the infusion of the $\mathbf{J}$ sample already contained a significantly higher amount of GA than the other teas, which may possibly explain this observation. According to Wang et al. [29] the extraction efficacy of GA at $T=90^{\circ} \mathrm{C}$ was twice that at $T=20^{\circ} \mathrm{C}$ under the same conditions. Thus, GA extraction should be more 
efficient with infusion than with maceration. Therefore, we hypothesize that the amounts present in the $\mathbf{J}$ tea leaves were higher than in the other samples and the high GA levels of $\mathbf{J}$ tea prevented the hydrolysis of the catechins during maceration. Hence, the amounts of GA and EGCG may explain, why maceration from the $\mathbf{J}(\mathbf{J} 2)$ sample was not significantly different from that prepared by infusion (J1) as shown by the matrix correlation analysis.

\subsubsection{Levels of Oxyaromatic Acids and Flavonols}

Table S1 lists the amount of flavonols and oxyaromatic acids found in the samples. Figure 4 is a graphical representation of the results for the several extracts, with data previously obtained for the Azores tea included. The graphic representation of Figure $3 \mathrm{~d}$ shows the amounts of GA for all the samples.

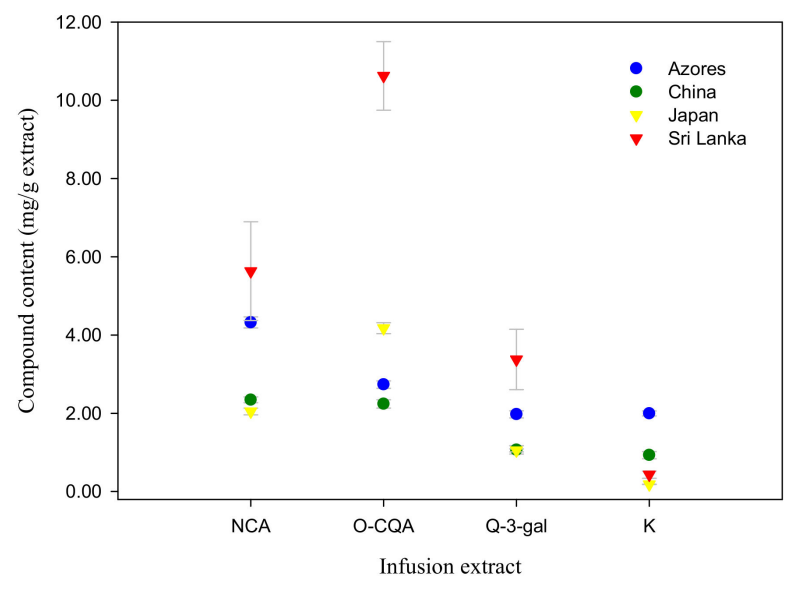

(a)

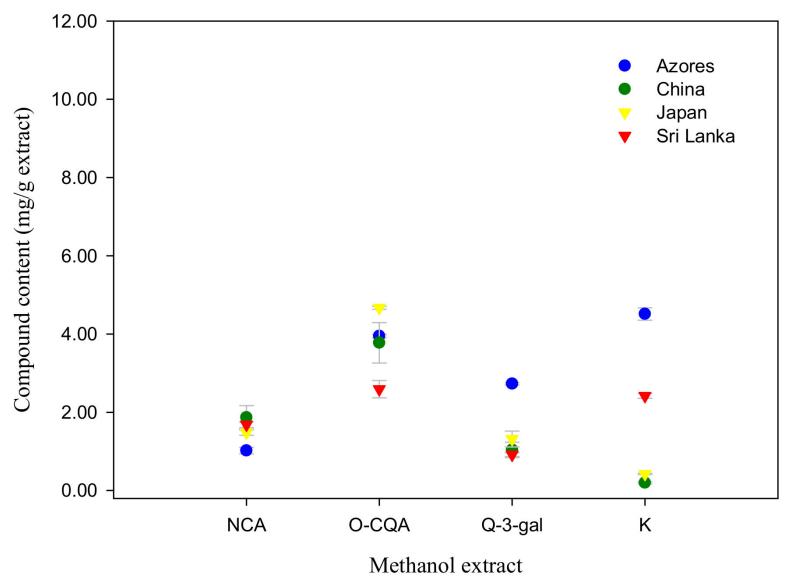

(b)

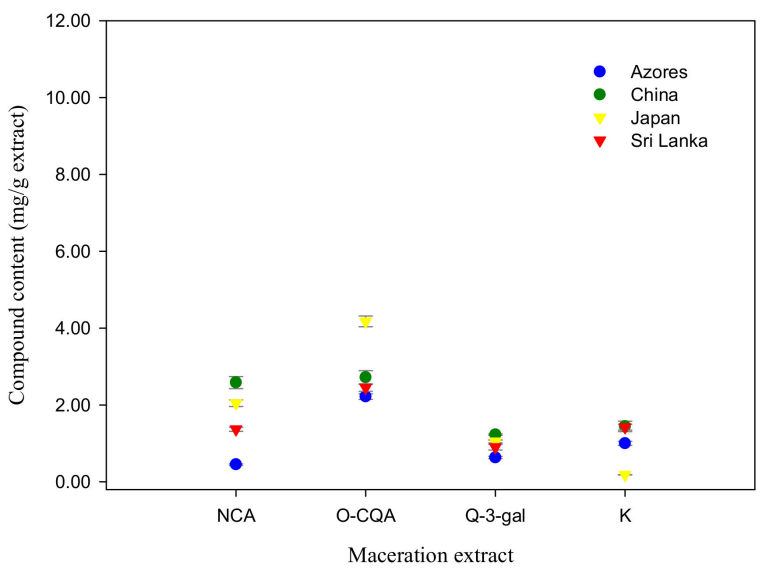

(c)

Figure 4. Content of o-Caffeoylquinic (o-CQA), gallic (GA) acids, quercetin-3-D-galactoside (Q-3-gal), kaempferol-3-glucoside (K) and neochlorogenic acid (NCA) in green teas expressed in $\mathrm{mg} /(\mathrm{g}$ of extract), determined by HPLC. (a) Infusions; (b) Methanolic extractions; (c) Macerations.

As said, the GA amounts were higher in all macerated tea samples, probably because the GA partly came from the hydrolysis process of other phenols. Concerning the remaining oxyaromatic acids, infusion was more effective on the extraction of those compounds.

The values for NCA varied from $3.1 \pm 0.1$ to $5.6 \pm 1.6 \mathrm{mg} / \mathrm{g}$ for infusions; from $1.4 \pm 0.1$ to $2.6 \pm 1.2 \mathrm{mg} / \mathrm{g}$ for macerations (the A2 sample has $0.5 \pm 0.2$ ) and from $1.5 \pm 0.1$ to $2.9 \pm 0.3$ for methanolic extractions. Those of o-CQA were found in higher amounts 
in the infusion of the SL tea. The quantities of the compound varied between 2.2 and $4.7 \mathrm{mg} / \mathrm{g}$ in the remaining samples.

Caffeoylquinic acids are envisaged to exert a wide range of potential benefits with therapeutic applications against Alzheimer disease [30] and for neuroprotection [31]. Most studies indicated that only small amounts of caffeic acid (the hydrolysis product of caffeoylquinic acids) are identified in urine or human plasma after oral intake. Therefore, it was concluded that ingested o-CQA is poorly absorbed (less than $1 \%$ ) in animals and humans [32-34].

The compound NCA can be absorbed either without transformation, or it undergoes hydrolysis and conjugation in the stomach and small intestine. Absorbed metabolites reach the maximum serum concentration within $1-2 \mathrm{~h}$ and are cleared from plasma within 5 to $6 \mathrm{~h}$. Alternatively, NCA can be subjected to microbiota-mediated metabolism, and the $C_{\max }$ will be observed after 5-6 h after ingestion, and metabolites could be present in plasma for 1 day. The amount excreted can vary between 10 to $80 \%$ depending on the amounts of fat and sugar consumed [35].

Some studies have pointed out that most of the ingested o-CQA amounts were degraded during digestion, metabolized by the intestinal microflora, and/or excreted with faeces. However, other studies with roasted and green coffee extracts showed that considerable o-CQA amounts could be identified in human plasma [36,37]. Therefore, the question of what benefits of o-CQA can be obtained by consuming green tea remains open to discussion.

The quantity of Q-3-gal extracted by maceration, methanol and infusion was about the same order of magnitude, varying between 0.9 and $1.3 \mathrm{mg} / \mathrm{g}$ except for the $\mathbf{J 1}$ and A3 samples that contained a slightly higher amount $(\sim 3.3 \mathrm{mg} / \mathrm{g})$. Q-glucosides undergo hydrolysis and set quercetin free during absorption in the gastrointestinal tract. Quercetin inhibited the oxidation process of LDL in vitro at a concentration of about $8 \mathrm{mg} / \mathrm{L}$, which is in the physiological range of quercetin's bioavailability [38], thus, contributing to the prevention of cardiovascular injuries. It also seems that the bioavailability of quercetin did not significantly change with the type of conjugated glucosides [39]. Thus, the bioavailability of Q-3-gal may be assumed to be similar to the other conjugates. Previous studies have suggested that after ingestion of about $150 \mathrm{mg}$ quercetin-3-glucoside, the plasma concentration peak of quercetin occurred between 20 to $60 \mathrm{~min}$ with concentrations around $1.3 \mathrm{mg} / \mathrm{L}$. Therefore, the Q-3-gal present in the studied samples, especially concerning infusions, might be effective in the prevention of cardiovascular diseases.

The levels of $\mathrm{K}$ detected in the extracts were similar to those of Q-3-gal. They varied within the 0.2 to $2.5 \mathrm{mg} / \mathrm{g}$ range, except for the methanolic extract of the A sample, that was higher.

The intake of kaempferol-rich plants has been related with cardiovascular benefits. Some studies have examined the potential cardiovascular effects of kaempferol, and it seems that intake of plant source dosages of was effective due to the higher bioavailability conferred by the gluco-conjugate when compared to the aglycone form [40]. Both in vitro and animal studies have indicated that the potential heart protection of kaempferol may be attributed to its anti-inflammatory activities [41,42].

Anyhow, studies evaluating the bioavailability of food-derived kaempferol conjugates are limited. In a crossover study, De Varies et al. [43] examined the digestion and absorption of kaempferol after intake of $27 \mathrm{mg}$ of kaempferol from black tea for three days. This quantity was about tenfold the amount present in the analysed samples. The urinary excretion was $2.5 \%$ of the amount ingested suggesting that kaempferol absorption was higher than quercetin ( $0.5 \%$ urinary excretion). This indicated that the type of glycoside in tea could have a higher bioavailability, although the quercetin content was higher in the aqueous extracted tea samples. This was confirmed in another study, which examined the rate of digestion and absorption of kaempferol after intake of $9 \mathrm{mg}$ kaempferol from cooked endive [44]. The 24-h urinary excretion of kaempferol was $1.9 \%$ and the plasma peak concentration reached $0.1 \mu \mathrm{M}$ after $5.8 \mathrm{~h}$. 


\subsubsection{Levels of L-Theanine}

Figure 5 shows the quantified amounts of L-theanine represented graphically. Theanine was undetectable in methanolic extracts and higher in maceration for teas from the Azores, Japan, and Sri Lanka.

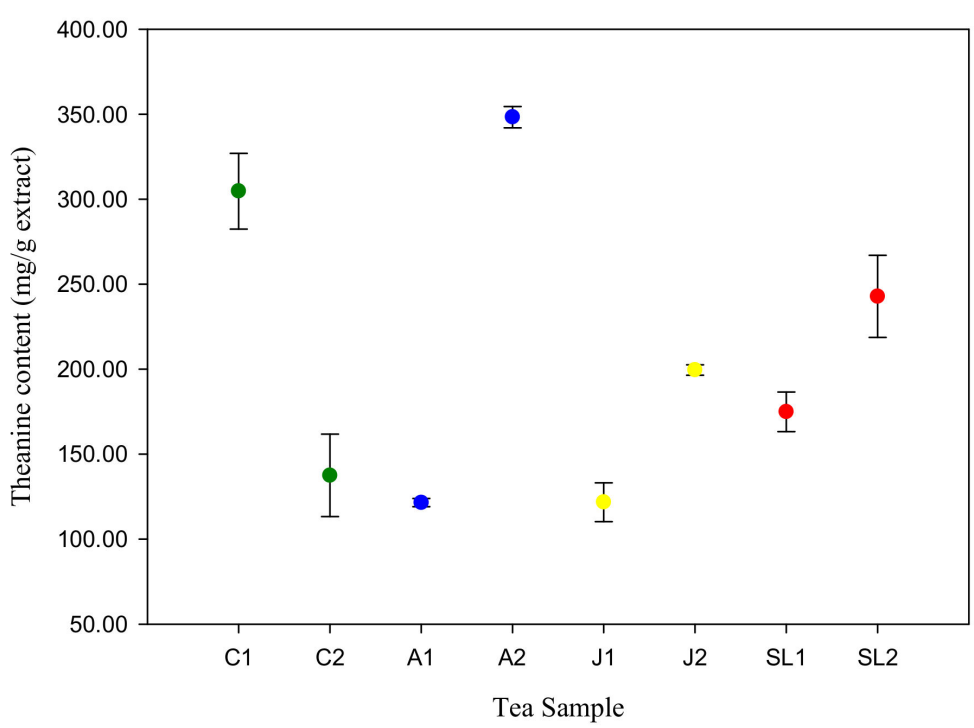

Figure 5. Content of theanine in green teas expressed in $\mathrm{mg} / \mathrm{g}$ of extract for infusions and macerations, determined by HPLC. C-China tea (in green); A-Azores tea (in blue); J-Japan tea (in yellow); SL-Sri Lanka Tea (in red); 1-Infusion; 2-Maceration.

L-theanine, a typical amino-acid of green tea has been widely studied due to its beneficial properties for humans, as it interacts in diverse physiological and biochemical pathways: among others, L-theanine has been shown to elicit a significant effect on the general state of mental alertness by increasing $\alpha$-wave brain activity and the reduction of anxiety [45]. Further, it was linked to the inhibition of the in vivo and ex vivo growth of human non-small cell lung cancer and leukaemia cell lines, as well as with the induction of apoptosis in four cancer cell lines of breast, colon, hepatoma, and prostate [46]. The amounts of theanine were higher upon maceration for all samples except for the Chinese tea. However, the contents were higher than $100 \mathrm{mg} / \mathrm{g}$ extract for all samples.

The most recent study made of the uptake kinetics of theanine (L-Glutamic acid $\gamma$-(ethylamide)) [47] suggested that L-theanine is rapidly absorbed with its maximum plasma concentration occurring $0.8 \mathrm{~h}$ after intake of $100 \mathrm{mg}$, but also is rapidly hydrolysed into ethylamine and glutamic acid (ethylamine and glutamic acid increased in plasma and were excreted by urine). Furthermore, a minor part of L-theanine was not hydrolysed and may be retained in erythrocytes. Thus, the functional effects of L-theanine intake may result from L-theanine, ethylamine, or glutamic acid.

\subsubsection{Levels of Alkaloids}

Caffeine was the most abundant xanthine (Table S2). There are numerous biological effects attributed to this molecule, as it exerts its effects on cognitive and physical function through adenosine A1 and A2a receptor blockade in the CNS and peripheral tissues. Methanolic extracts yielded significantly higher content of caffeine except in the SL tea (Table S2 and Figure 6). The concentration of extracted theophylline was similar in all extracts and provenances except for the infusion and methanolic extractions of the Azorian tea and for the infusion sample obtained with the Sri Lanka tea (Figure 6). 

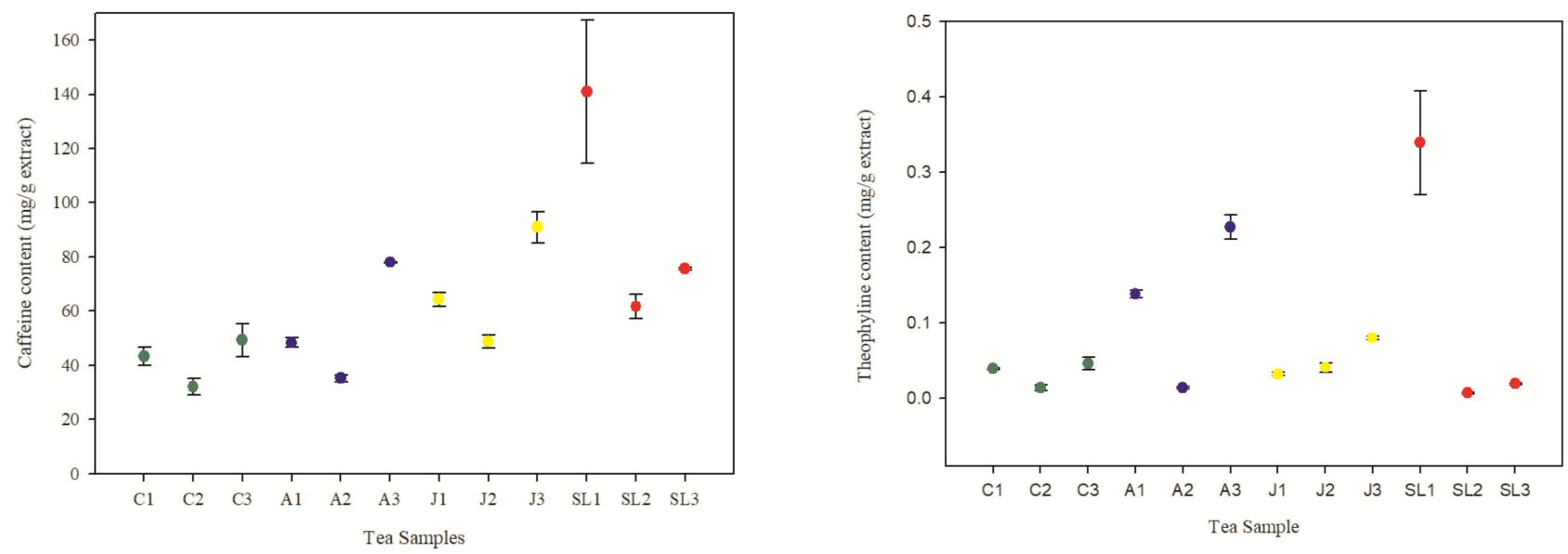

Figure 6. Graphical representation of the content caffeine and theophylline in green teas expressed in $\mathrm{mg} / \mathrm{g}$ of extract, determined by HPLC. C—China tea (in green); A-Azores tea (in blue); J-Japan tea (in yellow); SL-Sri Lanka Tea (in red); 1-Infusion; 2-Maceration; 3-Methanolic extract.

\section{Conclusions}

Phytochemical characterizations (catechins, oxyaromatic acids, flavonols, alkaloids and theanine) and total phenolic contents (TPC) of aqueous (infusion and maceration) and methanolic extracts of Camellia sinensis samples from different provenances (China, Japan and Sri Lanka) were performed. The Azorean tea displayed the highest TPC value. Also, for all teas TPC followed the trend TPC ${ }_{\text {Infusions }}>\mathrm{TPC}_{\text {Macerations }}>\mathrm{TPC}_{\text {Methanol }}$.

The levels of catechins, flavonols and oxyaromatic acids obtained for extract samples deriving from different areas were compared by a correlation matrix method, which showed similar compositions of the infusions and methanolic samples, while extractions made by maceration were significantly different. Maceration extracts of the samples from the Azores and Sri Lanka were also significantly different from those from China and Japan. The differences can be partially explained by the amounts of EGCG, ECG and GA found in the samples. While catechins approach $90 \%$ of the total measured phenols in infusions and methanolic extracts, the percentage lowers significantly in macerations due to the lower amount of catechins present in A, C and SL samples and due to the high amount of GA, suggesting the occurrence of hydrolysis during the long period of contact of tea leaves with water. Japanese tea is an exception, which could be related to the fact that Japan tea has higher amounts of GA in the leaves than the others. These results highlight the importance of continuing the extraction by infusion in tea processing to obtain the "instant tea". In particular, for EGCG, the catechin to which many of health benefits are attributed, the maceration process can lower 4 - to 5 -fold the quantity obtained compared with infusion. It should be noted that methanol is also effective in extraction of $C$.

L-theanine, was present in higher amounts in the Chinese tea sample, if it was obtained by infusion. In contrast, more theanine was extracted by maceration than by infusion in teas from the Azores, Japan, and Sri Lanka. The content of caffeine and theophylline was not significantly different in the analysed samples, but the trend methanolic < infusions < macerations was observed, with the exception of the SL tea.

Infusion compositions of $\mathbf{A}$ tea are not significantly different from those of $\mathbf{C}$ tea. The SL tea has higher amount of caffeine than others and $\mathbf{J}$ tea has more GA.

The art of cultivating tea was introduced to the Azores by Chinese experts at the end of the 19th century. Tea in China, Indonesia and Japan is cultivated in areas with high humidity in acidic soils and with well-marked dry and rainy seasons. In contrast, the Azores has volcanic soils, mild climate with temperatures varying between $13{ }^{\circ} \mathrm{C}$ to $26^{\circ} \mathrm{C}$ and with relative humidity of the air quite constant throughout the year, not reaching the saturation. Despite the climatic differences, the phytochemical characterization concerning the typical substances of green tea (catechins and theanine) revealed that tea from the Azores compares 
well with those coming from China and Japan. However, the characteristic climate of the Azores prevents the appearance of red spider and other pests that tend to appear during the rainy seasons. Thus, the production can be carried without resorting to fungicides and pesticides allowing to offer a high-quality organic tea.

The work here presented highlights the importance of the processing methodology to obtain "instant tea": the composition of the extracts obtained with the same methodology was not significantly affected by the provenance of the tea. However, attention should be drawn to the specificities of the Japanese samples (the tea analysed in the present work was of Sencha quality). In contrast, the extraction methodology significantly affected the phytochemical composition, especially concerning the polyphenols content. As such, our results indicate that instant tea classification based on chemical composition is sensible, but there is a need for a standard extraction methodology, namely concerning the temperature and time of contact of the tea leaves with the extraction solvent. For this work, representative samples were obtained from Portugal, but to confirm these trends, it is necessary to perform comparative analysis with more samples sold in other countries.

Supplementary Materials: The following are available online at https:/ /www.mdpi.com/article/10 $.3390 /$ beverages $8010013 / \mathrm{s} 1$, Table S1: Content of catechins in green teas in $\mathrm{mg} / \mathrm{g}$ of extract of the samples, determined by HPLC (mg/g extract); C—China tea; A-Azores tea; J-Japan tea; SL—Sri Lanka Tea; 1-Infusion; 2-Maceration; 3-Methanolic extract.; TCC - total catechins; TPC—Total phenolic content, Table S2: Content of L-theanine, caffeine and theophylline in green teas expressed in $\mathrm{mg} / \mathrm{g}$ of extract. C—China tea; A-Azores tea; J-Japan tea; SL-Sri Lanka Tea; 1-Infusion; 2-Maceration; 3-methanolic extract.

Author Contributions: Conceptualization, L.R.G.; data curation, S.B. and A.M.N.S.; formal analysis, L.R.G.; investigation, S.B., C.M., E.-J.S. and M.-E.F.H.; methodology, S.B., A.M.N.S. and C.M.; project administration, L.R.G.; resources, T.E.; writing—original draft, L.R.G.; writing—review and editing, C.M. and T.E. All authors have read and agreed to the published version of the manuscript.

Funding: This work received financial support from PT national funds (FCT/MCTES, Fundação para a Ciência e Tecnologia and Ministério da Ciência, Tecnologia e Ensino Superior) through projects UID/Multi/04546/2013 and UIDB/50006/2020 I UIDP/50006/2020.

Institutional Review Board Statement: Not applicable.

Informed Consent Statement: Not applicable.

Data Availability Statement: The authors declare that the data supporting the findings of this study are available within the article.

Conflicts of Interest: The authors declare no conflict of interest.

Ethical Approval: This article does not contain any studies with human participants or animals performed by any of the authors.

Statements and Declarations : Authors do not have financial or non-financial interests that are directly or indirectly related to the work submitted for publication.

\section{References}

1. Rakesh, C.; Sandeep, G.; Jasleen, K.; Kulbhushan, R.; Anshu, A.; Ujjwal, S. Green tea: A whole body health tonic: A review. Pharma Sci. Monit. 2017, 8, 362-372.

2. Filippini, T.; Malavolti, M.; Borrelli, F.; Izzo, A.A.; Fairweather-Tait, S.J.; Horneber, M.; Vinceti, M. Green tea (Camellia sinensis) for the prevention of cancer. Cochrane Database Syst. Rev. 2020, 3, CD005004. [PubMed]

3. Musial, C.; Kuban-Jankowska, A.; Gorska-Ponikowska, M. Beneficial Properties of Green Tea Catechins. Int. J. Mol. Sci. 2020, 21, 1744. [CrossRef]

4. Abe, S.K.; Inoue, M. Green tea and cancer and cardiometabolic diseases: A review of the current epidemiological evidence. Eur. J. Clin. Nutr. 2021, 75, 865-876. [CrossRef]

5. Miyata, Y.; Shida, Y.; Hakariya, T.; Sakai, H. Anti-Cancer Effects of Green Tea Polyphenols against Prostate Cancer. Molecules 2019, 24, 193. [CrossRef]

6. Yang, C.S.; Zhang, J.S. Studies on the prevention of cancer and cardio-metabolic diseases by tea: Issues on mechanisms, effective doses, and toxicities. J. Agric. Food Chem. 2019, 67, 5446-5456. [CrossRef] [PubMed] 
7. Yin, J.; Duan, S.; Liu, F.C.; Yao, Q.K.; Tu, S.; Xu, Y.; Pan, C.W. Blood pressure is associated with tea consumption: A cross-sectional study in a rural, elderly population of Jiangsu China. J. Nutr. Health Aging 2017, 21, 1151-1159. [CrossRef] [PubMed]

8. Xu, R.; Yang, K.; Ding, J.; Chen, G. Effect of green tea supplementation on blood pressure: A systematic review and meta-analysis of randomized controlled trials. Medicine 2020, 99, e19047. [CrossRef]

9. $\quad$ Abe, S.K.; Saito, E.; Sawada, N.; Tsugane, S.; Ito, H.; Lin, Y.; Tamakoshi, A.; Sado, J.; Kitamura, Y.; Sugawara, Y.; et al. Green tea consumption and mortality in Japanese men and women: A pooled analysis of eight population-based cohort studies in Japan. Eur. J. Epidemiol. 2019, 34, 917-926. [CrossRef]

10. Odegaard, A.O.; Koh, W.P.; Yuan, J.M.; Pereira, M.A. Beverage habits and mortality in Chinese adults. J. Nutr. 2015, 145, 595-604 [CrossRef]

11. Yan, Y.; Sui, X.; Yao, B.; Lavie, C.J.; Blair, S.N. Is There a Dose-Response Relationship between Tea Consumption and All-Cause, CVD, and Cancer Mortality? J. Am. Coll. Nutr. 2017, 36, 281-286. [CrossRef] [PubMed]

12. Shin, S.; Lee, J.E.; Loftfield, E.; Shu, X.O.; Abe, S.K.; Rahman, M.S.; Saito, E.; Islam, M.R.; Tsugane, S.; Sawada, N.; et al. Coffee and tea consumption and mortality from all causes, cardiovascular disease and cancer: A pooled analysis of prospective studies from the Asia Cohort Consortium. Int. J. Epidemiol. 2021, 1, dyab161. [CrossRef]

13. Zhao, L.G.; Li, H.L.; Sun, J.W.; Yang, Y.; Ma, X.; Shu, X.O.; Zheng, W.; Xiang, Y.B. Green tea consumption and cause-specific mortality: Results from two prospective cohort studies in China. J. Epidemiol. 2017, 27, 36-41. [CrossRef] [PubMed]

14. Liu, J.; Bodnar, B.H.; Meng, F.; Khan, A.I.; Wang, X.; Saribas, S.; Wang, T.; Lohani, S.C.; Wang, P.; Wei, Z.; et al. Epigallocatechin Gallate from Green Tea Effectively Blocks Infection of SARS-CoV-2 and New Variants by Inhibiting Spike Binding to ACE2 Receptor. Cell Biosci. 2021, 11, 168. [CrossRef] [PubMed]

15. Barreira, S.; Moutinho, C.; Silva, A.; Neves, J.; Seo, E.; Hegazy, E.; Efferth, E.; Gomes, L.R. Phytochemical characterization and biological activities of green tea (Camellia sinensis) produced in the Azores, Portugal. Phytomed. Plus 2021, 1, 100001. [CrossRef]

16. Luthria, D.L.; Mukhopadhyay, S.; Krizek, D. Content of total phenolics and phenolic acids in tomato (Lycopersicon esculentum Mill.) fruits as influenced by cultivar and solar UV radiation. J. Food Compos. Anal. 2006, 19, 771-777. [CrossRef]

17. Song, R.; Kelman, D.; Johns, K.L.; Wright, A.D. Correlation between Leaf Age, Shade Levels and Characteristic Beneficial Natural Constituents of Tea (Camellia sinensis) Grown in Hawaii. J. Food Chem. 2012, 133, 707-714. [CrossRef]

18. Lee, L.-S.; Kim, S.-H.; Kim, Y.-B.; Kim, Y.C. Quantitative Analysis of Major Constituents in Green Tea with Different Plucking Periods and Their Antioxidant Activity. Molecules 2014, 19, 9173-9186. [CrossRef]

19. Xu, B.J.; Chang, S.K. A comparative study on phenolic profiles and antioxidant activities of legumes as affected by extraction solvents. J. Food Sci. 2007, 72, 159-166. [CrossRef]

20. Uchenna, J.; Unachukwu, S.A.; Kavalier, A.; Lyles, J.T.; Kennelly, E.J. White and Green Teas (Camellia sinensis var. sinensis): Variation in Phenolic, Methylxanthine and Antioxidant Profiles. J. Food Sci. 2010, 75, C541-C548.

21. Chen, Z.-Y.; Zhu, Q.Y.; Tsang, D.; Huang, Y. Degradation of Green Tea Catechins in Tea Drinks. J. Agric. Food Chem. 2001, 49, 477-482. [CrossRef] [PubMed]

22. Komes, D.; Horžić, D.; Belščak, A.; Ganić, K.; Vulić, K.I. Green tea preparation and its influence on the content of bioactive compounds. Int. Food Res. J. 2010, 43, 167-176. [CrossRef]

23. Yashin, A.Y.; Nemzer, B.V.; Combet, E.; Yashin, Y.I. Determination of the Chemical Composition of Tea by Chromatographic Methods: A Review. J. Food Res. 2015, 4, 58-88. [CrossRef]

24. Reygaert, W.C. Green Tea Catechins: Their Use in Treating and Preventing Infectious Diseases. Biomed Res. Int. 2018, 2018, 9105261. [CrossRef]

25. Zinellu, A.; Sotgia, S.; Scanu, B.; Forteschi, M.; Giordo, R.; Cossu, A.; Posadino, A.M.; Carru, C.; Pintus, G. Human Serum Albumin Increases the Stability of Green Tea Catechins in Aqueous Physiological Conditions. PLoS ONE 2015, 10, e0134690. [CrossRef]

26. Clifford, M.N.; van der Hooft, J.J.; Crozier, A. Human studies on the absorption, distribution, metabolism, and excretion of tea polyphenols. Am. J. Clin. Nutr. 2013, 98 (Suppl. 6), 1619S-1630S. [CrossRef]

27. Renouf, M.; Marmet, C.; Guy, P.A.; Beaumont, M.; Lepage, M.; Williamson, G.; Dionisi, F. Dose-response plasma appearance of green tea catechins in adults. Mol. Nutr. Food Res. 2013, 57, 833-839. [CrossRef]

28. Battestin, V.; Macedo, G.A.; De Freitas, V.A.P. Hydrolysis of epigallocatechin gallate using a tannase from Paecilomyces variotii. J. Food Chem. 2008, 108, 228-233. [CrossRef]

29. Wang, X.; Cai, C.; Li, X. Optimal Extraction of Gallic Acid from Suaeda glauca Bge. Leaves and Enhanced Efficiency by Ionic Liquids. Int. J. Chem. Eng. 2016, 2016, 5217802. [CrossRef]

30. Matthews, D.G.; Caruso, M.; Alcazar, M.A.; Wright, K.M.; Maier, C.S.; Stevens, J.F.; Gray, N.E.; Quinn, J.F.; Soumyanath, A Caffeoylquinic Acids in Centella asiatica Reverse Cognitive Deficits in Male 5XFAD Alzheimer's Disease Model Mice. Nutrients 2020, 12, 3488. [CrossRef]

31. Sasaki, K.; Davies, J.; Doldan, N.G.; Arao, S.; Ferdousi, F.; Szele, F.G.; Isoda, H. 3,4,5-Tricaffeoylquinic acid induces adult neurogenesis and improves deficit of learning and memory in aging model senescence-accelerated prone 8 mice. Aging 2019, 11, 401-422. [CrossRef] [PubMed]

32. Bourne, L.C.; Rice-Evans, C.A. Urinary detection of hydroxycinnamates and flavonoids in humans after highdietary intake of fruit. Free Radic. Res. 1998, 28, 429-438. [CrossRef] [PubMed] 
33. Spencer, J.P.; Chowrimootoo, G.; Choudhury, R.; Debnam, E.S.; Srai, S.K.; Rice-Evans, C. The small intestine can both absorb and glucuronidate luminal flavonoids. FEBS Lett. 1999, 458, 224-230. [CrossRef]

34. Dupas, C.; Baglieri, A.M.; Ordonaud, C.; Tom, D.; Maillard, M. Chlorogenic acid is poorly absorbed, independently of the food matrix: A Caco-2 cells and rat chronic absorption study. Mol. Nutr. Food Res. 2006, 50, 1053-1060. [CrossRef]

35. Clifford, M.N.; Kerimi, A.; Williamson, G. Bioavailability and metabolism of chlorogenic acids (acyl-quinic acids) in humans. Compr. Rev. Food Sci. Food Saf. 2020, 19, 1299-1352. [CrossRef]

36. Monteiro, M.; Farah, A.; Perrone, D.; Trugo, L.C.; Donangelo, C. Chlorogenic acid compounds from coffee are differentially absorbed and metabolized in humans. J. Nutr. 2007, 137, 2196-2221. [CrossRef]

37. Farah, A.; Monteiro, M.; Donangelo, C.M.; Lafay, S. Chlorogenic acids from green coffee extract are highly bioavailable in humans. J. Nutr. 2008, 138, 2309-2315. [CrossRef]

38. Manach, C.; Morand, C.; Crespy, V.; Demigne, C.; Texier, O.; Regerat, F.; Remesy, C. Quercetin is recovered in human plasma as conjugated derivatives which retain antioxidant properties. FEBS Lett. 1998, 426, 331-336. [CrossRef]

39. Olthof, M.R.; Hollman, P.C.; Vree, T.B.; Katan, M.B. Bioavailabilities of Quercetin-3-Glucoside and Quercetin-4'-Glucoside Do Not Differ in Humans. J. Nutr. 2000, 130, 1200-1203. [CrossRef]

40. Geleijnse, J.M.; Launer, L.J.; Van der Kuip, D.A.M.; Hofman, A.; Witteman, J.C.M. Inverse association of tea and flavonoid intakes with incident myocardial infarction: The Rotterdam Study. Am. J. Clin. Nutr. 2002, 75, 880-886. [CrossRef]

41. Kampkötter, A.; Gombitang, N.; Kwonkam, C.; Zurawski, R.F.; Timpel, C.; Chovolou, Y.; Wätjen, W.; Kahl, R. Effects of the flavonoids kaempferol and fisetin on thermotolerance, oxidative stress and FoxO transcription factor DAF-16 in the model organism Caenorhabditis elegans. Arch. Toxicol. 2007, 81, 849-858. [CrossRef] [PubMed]

42. Dabeek, W.M.; Marra, M.V. Dietary Quercetin and Kaempferol: Bioavailability and Potential Cardiovascular-Related Bioactivity in Humans. Nutrients 2019, 11, 2288. [CrossRef] [PubMed]

43. De Vries, J.H.; Hollman, P.C.; Meyboom, S.; Buysman, M.N.; Zock, P.L.; van Staveren, W.A.; Katan, M.B. Plasma concentrations and urinary excretion of the antioxidant flavonols quercetin and kaempferol as biomarkers for dietary intake. Am. J. Clin. Nutr. 1998, 68, 60-65. [CrossRef] [PubMed]

44. DuPont, M.S.; Day, A.J.; Bennett, R.N.; Mellon, F.A.; Kroon, P.A. Absorption of kaempferol from endive, a source of kaempferol-3glucuronide, in humans. Eur. J. Clin. Nutr. 2004, 58, 947-954. [CrossRef]

45. Kelly, S.P.; Gomez-Ramirez, M.; Montesi, J.L.; Foxe, J.J. L-theanine and caffeine in combination affect human cognition as evidenced by oscillatory alpha-band activity and attention task performance. J. Nutr. 2008, 138, 1572S-1577S. [CrossRef]

46. Calgarotto, A.K.; Maso, V.; Junior, G.C.F.; Nowill, A.E.; Filho, P.L.; Vassallo, J.; Saad, S.T.O. Antitumor activities of Quercetin and Green Tea in xenografts of human leukemia HL60 cells. Sci. Rep. 2018, 8, 3459. [CrossRef]

47. Scheid, L.; Ellinger, S.; Alteheld, B.; Herholz, H.; Ellinger, J.; Henn, T.; Helfrich, H.P.; Stehle, P. Kinetics of L-Theanine Uptake and Metabolism in Healthy Participants Are Comparable after Ingestion of L-Theanine via Capsules and Green Tea. J. Nutr. 2012, 142, 2091-2096. [CrossRef] 